\title{
An Unusual Presentation of Oral Squamous Cell Carcinoma: A Case Report
}

\author{
Rashmi Gangavatia, c, Rajendra Baad ${ }^{\mathrm{a}}$, Nupura Vibhute ${ }^{\mathrm{a}}$, Siddhartha Varma ${ }^{\mathrm{b}}$
}

\begin{abstract}
Squamous cell carcinoma (SCC) is the most common malignant tumor of the oral cavity and is a potentially fatal disease that proved to be a bane to clinicians throughout the world. In spite of various treatment modalities to manage oral SCC, one key factor for the prognosis is the early detection. Over the past two decades, there has been a surge in the investigations conducted pertaining specifically to oral cancer. Therefore, the purpose of the current case report is to focus on the use of newer techniques like immunohistochemistry (IHC) which is a valuable tool in diagnosing cases with atypical presentation.
\end{abstract}

Keywords: Oral squamous cell carcinoma; Prognosis; Immunohistochemistry

\section{Introduction}

Oral cancer is the sixth most common cancer worldwide and squamous cell carcinoma (SCC) accounts for $90 \%$ of these cases [1-3]. The highest incidence and prevalence of oral SCC (OSCC) is found in the Indian subcontinent where the risk of developing OSCC is increased due to deleterious habits of chewing tobacco, betel quid and areca-nut. An alarming observation is an increased incidence and prevalence of OSCC particularly in younger persons. In India, cancer of the oral cavity is one of the five leading sites of cancer in either gender. More than $90 \%$ of the oral cancers occur in patients over the age of 45 , with a male predilection $[4,5]$. Oral cancer is definitely a preventable condition, due to the possibility of early detection and prompt treatment. However, majority of the cases are de-

Manuscript accepted for publication April 29, 2016

aDepartment of Oral Pathology and Microbiology, School of Dental Sciences, KIMSDU, Karad, India

bepartment of Periodontology, School of Dental Sciences, KIMSDU, Karad, India

${ }^{\mathrm{c} C}$ Corresponding Author: Rashmi Gangavati, Department of Oral Pathology and Microbiology, School of Dental Sciences, KIMSDU, Karad, India.

Email: siddhartha_varma@yahoo.co.in

doi: http://dx.doi.org/10.14740/jmc2497w tected at a much advanced stage leading to poor prognosis and low survival rate of the patients. Over the past two decades, there has been a surge in the investigations conducted pertaining specifically to oral cancer. Therefore, the purpose of the current case report is to focus on the use of newer techniques like immunohistochemistry (IHC) which is a valuable tool in diagnosing cases with atypical presentation.

\section{Case Report}

A 45-year-old female patient reported with chief complaint of severe burning sensation and discomfort in her tongue since 6 months. She first noticed an ulcer on posterior aspect of tongue which gradually increased to the present size (Fig. 1). The ulcer was associated with continuous and throbbing pain which radiated to left side of her face and aggravated on mastication. She experienced difficulty in swallowing and gradually experienced change in her voice. There was no significant medical history. On enquiry about adverse habits, patient reported use of mishri 4 - 5 times/day since past 25 years.

General physical examination revealed that the patient is moderately built and nourished and all the vital signs were within normal limits. Extraoral examination revealed bilaterally palpable, fixed and tender submandibular lymph nodes. Intraoral examination revealed ulceroproliferative growth on dorsal surface of tongue measuring approximately $3 \times 2 \mathrm{~cm}$ extending from posterior one-third of the tongue till oropharynx. Lesion was yellowish in color and covered with areas of

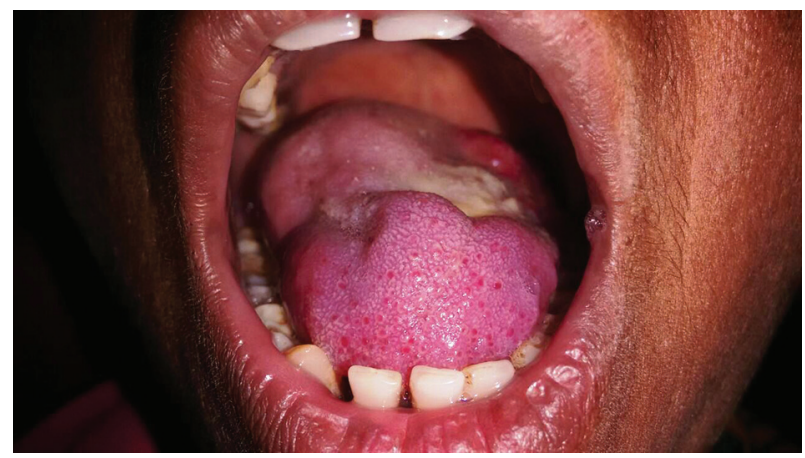

Figure 1. Ulceroproliferative growth on the posterior one-third of tongue. 


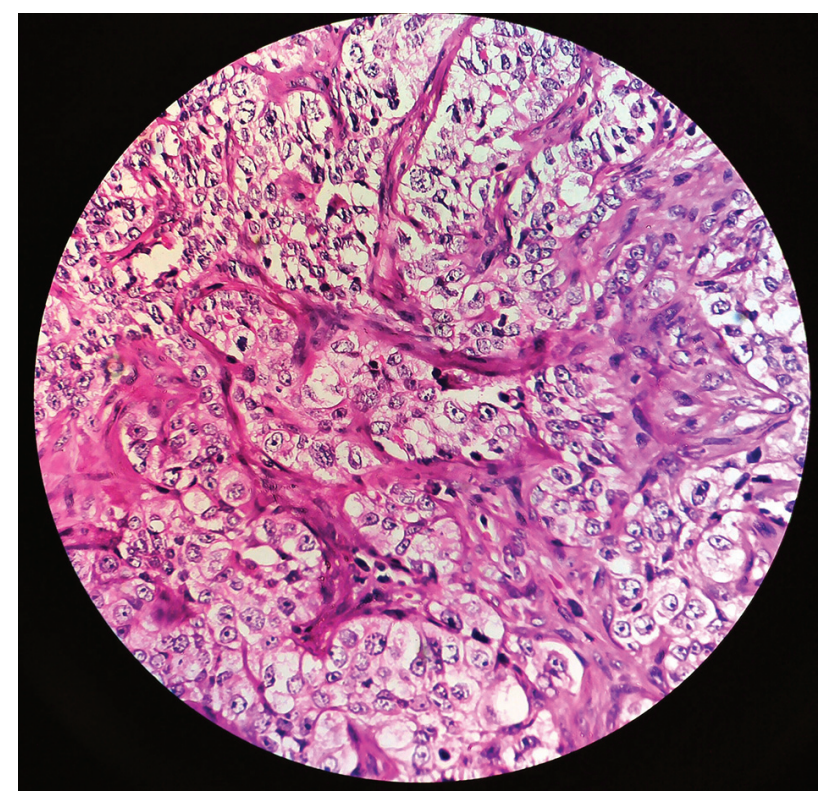

Figure 2. H\&E stained sections showing neoplastic cells at $\times 40$.

slough. Palpatory findings revealed induration and tenderness. A computed tomography $(\mathrm{CT})$ revealed ill defined heterogeneously enhancing lesion involving the left half of the oral tongue crossing the median raphe to reach right side of tongue anteriorly with areas of necrosis and multiple lymphadenopathy. Above features were suggestive of neoplastic etiology and patient was advised incisional biopsy.

On microscopic examination, H\&E stained sections showed neoplastic cells in the form of sheets, islands and strands in the connective tissue showing dysplastic features like increased nuclear cytoplasmic ratio, cellular pleomorphism, nuclear hyperchromatism and few mitotic figures. Individual cells were large and round having moderately pleomorphic hyperchromatic to vesicular nuclei with 2 - 4 prominent eosinophilic nucleoli and moderate amount of eosinophilic cytoplasm. The connective tissue showed numerous blood vessels, moderate chronic inflammatory cell infiltrate, collagen bundles and fibroblasts (Fig. 2).

Depending upon the histopathological findings, origin of the tumor could not be confirmed as similar findings are seen in some cases of soft tissue sarcomas. Therefore, to confirm the origin of the tumor, IHC was performed using markers like cytokeratin-7 (CK-7), vimentin and S-100.

IHC showed positivity for CK-7 (Fig. 3) that confirmed the epithelial origin of the tumor and hence diagnosed as of poorly differentiated SCC.

\section{Discussion}

Globally, about 275,000 new cases of OSCC are diagnosed each year but the incidence of OSCC shows large geographical variations [6]. Histopathologically, SCC is divided into three grades depending on the degree to which the tumor resembles the parent tissue and produces keratin. One which shows much

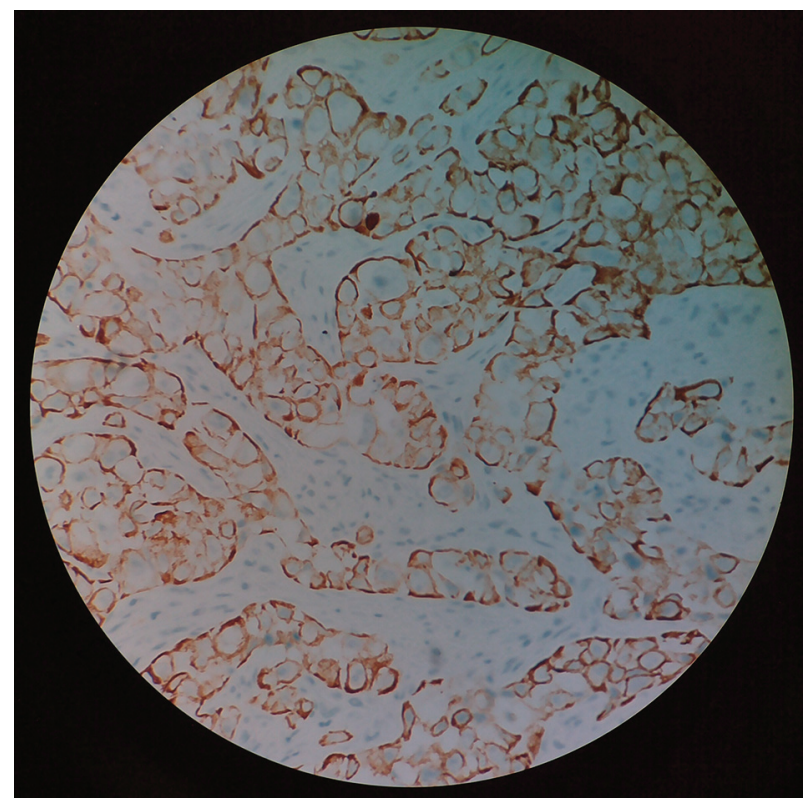

Figure 3. IHC showing positivity for cytokeratin-7.

cellular and nuclear pleomorphism that is, immature and bears no resemblance to the tissue of origin is designated as poorly differentiated [7]. Detection of malignancy before it arises would be the best possible way of preventing the dreaded disease in its earliest form. Malignant cells have different histologic and biochemical behavior as compared to their normal counterparts. Several abnormal cellular products are synthesized by neoplastic cells and by the body in presence of such an abnormal situation. These products that can be detected in various body fluids and on surface of cancer cells are called as tumor markers [8]. Keratins are defined as intermediate filament forming proteins with specific physicochemical properties produced in any vertebrate epithelia primarily responsible for maintaining the structural integrity of keratinocytes [9]. The different types of keratin and their associated proteins serve as important markers of differentiation and thus aid in diagnosis of various pathological conditions including cancer [10]. Few markers are specific for single individual tumor like, cytokeratins for detection of epithelial origin of tumor and vimentin for mesenchymal origin and S-100 for neural origin of tumor and many more [8]. In our case, CK-7 marker was used for detection of tumor origin.

IHC involves specific antigen-antibody reactions and has an apparent advantage over traditionally used special enzyme staining techniques that identify only a limited number of proteins, enzymes, and tissue structures [11]. Hence, IHC is widely used in many medical research laboratories as well as clinical diagnostics and could prove an important aid in situations like the present case where the routine histopathology is not conclusive enough.

\section{Conclusion}

Oral cancer continues to be a deadly disease for more than 
$50 \%$ of the cases diagnosed every year. This is due to the fact that most of these cases are diagnosed when they have already progressed to the advanced stage. Educating the general population about oral cancer is a must to combat mortality and morbidity arising out of it. Invention of new tumor markers with high sensitivity and specificity can lead to early detection of oral cancer and can minimize the damage.

\section{Conflicts of Interest}

None.

\section{References}

1. Shah JP, Gil Z. Current concepts in management of oral cancer - surgery. Oral Oncol. 2009;45(4-5):394-401.

2. Attar E, Dey S, Hablas A, Seifeldin IA, Ramadan M, Rozek LS, Soliman AS. Head and neck cancer in a developing country: a population-based perspective across 8 years. Oral Oncol. 2010;46(8):591-596.

3. Bagan J, Sarrion G, Jimenez Y. Oral cancer: clinical features. Oral Oncol. 2010;46(6):414-417.
4. Neville BW, Day TA. Oral cancer and precancerous lesions. CA Cancer J Clin. 2002;52(4):195-215.

5. Rapidis AD, Gullane P, Langdon JD, Lefebvre JL, Scully $\mathrm{C}$, Shah JP. Major advances in the knowledge and understanding of the epidemiology, aetiopathogenesis, diagnosis, management and prognosis of oral cancer. Oral Oncol. 2009;45(4-5):299-300.

6. Warnakulasuriya S. Global epidemiology of oral and oropharyngeal cancer. Oral Oncol. 2009;45(4-5):309-316.

7. Neville BW, Damm DD, Allen C, Bouquet J (2008). Oral and Maxillofacial Pathology, 2nd ed. Elsevier. pp. 451452.

8. Manikantan NS, Balakrishnan D, Kumar ADM, Shetty B. Tumor Markers: At a Glance. Oral Maxillofac Pathol J 2014;5(1):437-440.

9. Bragulla HH, Homberger DG. Structure and functions of keratin proteins in simple, stratified, keratinized and cornified epithelia. J Anat. 2009;214(4):516-559.

10. Moll R, Divo M, Langbein L. The human keratins: biology and pathology. Histochem Cell Biol. 2008;129(6):705733.

11. Duraiyan J, Govindarajan R, Kaliyappan K, Palanisamy M. Applications of immunohistochemistry. J Pharm Bioallied Sci. 2012;4(Suppl 2):S307-309. 